\title{
IMPROVED YOUNG AND HEINZ INEQUALITIES WITH THE KANTOROVICH CONSTANT
}

\author{
WENSHI LIAO AND JUNLIANG WU
}

Abstract. In this article, we study the further refinements and reverses of the Young and Heinz inequalities with the Kantorovich constant. These modified inequalities are used to establish corresponding operator inequalities on a Hilbert space and Hilbert-Schmidt norm inequalities. Mathematics subject classification (2010): 15A15, 15A42, 15A60, 47A30.

Keywords and phrases: Young inequality, Heinz mean, Kantorovich constant, operator inequalities.

\section{REFERENCES}

[1] M. Bakherad And M. S. Moslehian, Reverses and variations of Heinz inequality, Linear Multilinear Algebra 63, 10 (2015), 1972-1980.

[2] R. Bhatia And K. R. Parthasarathy, Positive definite functions and operator inequalities, Bull. London Math. Soc. 32, 2 (2000), 214-228.

[3] T. Furuta, J. Mićić Hot, J. PeČARIĆ And Y. Seo, Mond-Pečarić Method in Operator Inequalities, Element, Zagreb, 2005.

[4] S. FuruichI, On refined Young inequalities and reverse inequalities, J. Math. Inequal, 5, 1 (2011), 21-31.

[5] S. FurUichi, Refined Young inequalities with Specht's ratio, J. Egypt. Math. Soc. 20, 1 (2012), 46-49.

[6] R. A. Horn And C. R. Johnson, Matrix analysis, 2nd ed, Cambridge University Press, New York, 2013.

[7] O. Hirzallah And F. KitTaneh, Matrix Young inequalities for the Hilbert-Schmidt norm, Linear Algebra Appl. 308 (2000), 77-84.

[8] H. Kos AKI, Arithmetic-geometric mean and related inequalities for operators, J. Funct. Anal. 156, 2 (1998), 429-451.

[9] F. Kittaneh, M. KRnić, N. Lovričević And J. PeČARIć, Improved arithmetic-geometric and Heinz means inequalities for Hilbert space operators, Publ. Math. Debrecen. 80, 3-4 (2012), 465478.

[10] F. Kittaneh And M. Krnić, Refined Heinz operator inequalities, Linear Multilinear Algebra. 61, 8 (2013), 1148-1157.

[11] F. Kittaneh And Y. Manasrah, Improved Young and Heinz inequalities for matrices, J. Math. Anal. Appl. 361, 1 (2010), 262-269.

[12] F. Kittaneh And Y. ManasRah, Reverse Young and Heinz inequalities for matrices, Linear Multilinear Algebra. 59, 9 (2011), 1031-1037.

[13] M. KRniĆ, N. LOVRIČEviĆ, J. PeČARIĆ, Jensen's operator and applications to mean inequalities for operators in Hilbert space, Bull. Malays. Math. Sci. Soc. 35, 1 (2012), 1-14.

[14] M. TominaGA, Specht's ratio in the Young inequality, Sci. Math. Japon. 55, 3 (2002), 583-588.

[15] J. L. Wu AND J. G. ZHAO, Operator inequalities and reverse inequalities related to the KittanehManasrah inequalities, Linear Multilinear Algebra. 62, 7 (2014), 884-894.

[16] J. G. ZHAO AND J. L. WU, Operator inequalities involving improved Young and its reverse inequalities, J. Math. Anal. Appl. 421, 2 (2015), 1779-1789.

[17] H. L. Zuo, G. H. SHI AND M. FuJil, Refined Young inequality with Kantorovich constant, J. Math. Inequal. 5, 4 (2011), 551-556. 